\title{
Live Supervision: Developing Therapeutic Competence in Family Systems Nursing
}

Lorraine M. Wright, RN, PhD

Live supervision is the most important element in the achievement of therapeutic competence in family systems nursing. If family systems nurse educators adopt the belief that therapeutic competence is the primary goal for clinical practice with families, then live supervision will need to be provided for graduate nursing students.

\section{Family Systems Nursing}

Family systems nursing is the integration of nursing systems, cybernetics, and family therapy theories (Wright \& Leahey, 1990; Wright, Watson, \& Bell, 1990) and a meta-theory of cognition (Maturana \& Varela, 1992. Family systems nursing focuses on interaction and reciprocity, emphasizing the family as the unit of care.

This approach is in contrast to the nursing families, which focuses on the individual in the context of the family (Wright \& Leahey, 1990). Family systems nursing is a clinical specialization requiring graduatelevel education, which can be situated within any practice area of nursing (e.g., geriatric, mental health, surgical, community health).

\section{Beliefs about Family Systems Nursing Education and Supervision}

Family systems nursing education and supervision is based on several assumptions and beliefs. Some of these beliefs are:

1. Family systems nursing education needs to focus on interactional treatment approaches when physical illness is involved (Watson, 1987; Watson \& Nanchoff-Glatt, 1990; Wright, Bell, \& Rock, 1989: Wright, Miller, \& Nelson, 1985; Wright \& Simpson, 1991; Wright \& Watson, 1988). 2. Family systems nurse educators need to 
be expert clinicians willing to demonstrate their family interviews to their students.

3. Family systems nurse educators need to teach their students that family systems nursing skills are not simply additional techniques in their assessment and intervention repertoire, but rather the operationalization of new ways to conceptualize human problems, i.e., systemically and interactively.

4. Family systems nursing clinical skills (i.e., perceptual, conceptual, and executive) are best developed through the method of live supervision (Tomm \& Wright, 1979; Wright \& Leahey, 1984. 1988; Wright, Watson, \& Bell. 1990).

5. Nursing students are structurally determined, i.e., each student responds differently to the same information or perturbation, depending on their structure (Maturana \& Varela. 1992). Living systems cannot directly instruct, control, or change other systems (Maturana \& Varela; Wright \& Levac, 1992) and therefore there is no instructive interaction.

\section{Co-evolving a systemic lens of beliefs}

When a family presents with difficulties coping with a physical or mental health problem, assessment of the constraining and facilitative beliefs of family members about the health problem have proved useful (Wright \& Nagy, 1993: Wright \& Simpson, 1991; Wright \& Watson, 1988). As Family systems nurse interviewers, we are often invited by family members to adopt similar beliefs about the problem. Faculty and students co-evolve an ecology of beliefs about the families with whom they work. Just as a family's constraining beliefs about a problem (O'Hanlon \& Wilk, 1987; Watzlawick, Weakland, \& Fisch, 1974) restrict solutions, so too can students' beliefs about a particular family restrict therapeutic solutions. This does not preclude that a particular nursing 
student may have very facilitative beliefs starting a family interview, but frequently these beliefs are neutralized through the course of interaction with families.

One of the goals of supervision is to not only participate in the process of assisting families to alter their view of the presenting problem, but also to alter the student's view. Supervision is an enabling exercise aimed at shifting the nurse's notions about what they believe about what they are observing. If successful, a student completes the family interview with a fresh view of the problem because of new distinctions upon which to build further therapeutic distinctions. It will be necessary for nurse educators to defy the tyranny of conventional beliefs about helpfulness.

\section{Evolution of Supervision in Family Systems Nursing}

Nursing has been going through a clearly identifiable evolutionary process with regard to various types of family systems nursing supervision (Wright \& Leahey, 1984). Process recording has been heavily relied upon in the past. However, it has been mistakenly believed that dialogues of nurse - client interactions are true and accurate. I agree with Kubie (1958), who stated that "any true resemblance between the student's report and that which has taken place is almost a miraculous accident" (p. 230).

The use of process recording for the development of executive skills is the least desirable and least effective method. Audiotape supervision is a step improved to at least being able to "hear" what the student hears, but it does not allow for extremely valuable data concerning nonverbal behavior. There is also no opportunity for immediate feedback regarding the course of an interview or for the development of perceptual and conceptual skills. However, live supervision is the only method that provides immediate feedback for the development of executive skills, 
i.e., the actual actions or responses of the nurse, which includes both the nurse's internal affective reactions and overt therapeutic actions (Tomm \& Wright, 1979; Wright \& Leahey, 1984; Wright, Watson \& bell, 1990).

\section{Live Supervision}

Montalvo (1973) first coined the term "live supervision." Live supervision consists of a clinical supervisor observing a family interview from behind a one-way mirror. If one-way mirrors are not available, then the supervisor sits in the room with the supervisee. Live supervision has been an integral and highly valued method of supervision within the practice and profession of family therapy for 25 years.

Live supervision, within the context of nursing, had been used predominantly for the development of psychomotor skills. Nursing educators have dutifully and devotedly spent many hours providing supervision for nursing students in the development of their skills in changing dressings, inserting catheters, checking the fetal heartbeat, and so forth. However, nursing has never actively pursued supervision for the development of interpersonal skills. Very frequently have nurse educators actively pursued direct observation of nursing students' family interviews.

In a national survey of family nursing education in Canadian university faculties and schools of nursing, less than half reported using live supervision as the predominant method of supervision (Wright, Bell \& Rock, 1989). Case discussion and process recording were reported as the predominant method.

\section{Rationale for live supervision}

Live supervision is the most effective way to assist and monitor therapeutic competence in family systems nursing. To produce competent family systems nurse clinicians, nurse educators must observe clinical skill development. Live supervision is also effective for drawing the nurse's attention to underlying gender issues (Wheeler, Avid, Miller \& Chaney, 1985). As with any form of supervision, There are "muddles" or traps that nurse educators may encounter. One of the potential "muddles" of live supervision is the tendency toward "robotization" of the supervisee (Schwartz, Liddle \& Breunlin, 1988). Robotization occurs when a nursing student carries out the supervisor's every request and demonstrates little initiative 
or creativity. However, a certain amount of robotization is inevitable in love supervision. Robotization is perhaps even necessary when inexperienced or even experienced nurses are learning a new skill or a new way of relating (Wright, Luckhurst, \& Amundson, 1990). However, in a study that investigated 85 trainees' reactions to live supervision, the respondents frequently reported that in comparison to experiences with other types of supervision, live supervision facilitated a more clear focus during the interview, provided clearer direction for future sessions, and increased their feelings of appropriate and authoritarian personal power (Liddle, Davidson, \& Barrett, 1988).

\section{Live Supervision at the Family Nursing Unit}

The Family Nursing Unit (FNU) in the

Faculty of Nursing at University of Calgary is an

education and research outpatient unit

for the interactional study and treatment of families

with health problems (Wright, Watson, \& bell, 1990).

Master of Nursing students specializing in family systems

nursing spend two or three clinical practica in the

FNU assisting families who are experiencing

difficulties with physical and/or emotional health problems.

The FNU has a suite of five interviewing rooms, one large observation room, and a central control room.

Each room has a one-way mirror enabling live supervision of family interviews from the large observation room. All the rooms are connected to the observation room by a telephone intercom system. All of the family interviews are videotaped for student review after sessions. A faculty supervisor is able to communicate directly with the graduate student conducting the family interview through the use of a telephone intercom system.

\section{Live supervision operationalized at the FNU}

In order to "see" what our students "see", we divide each interview into five parts: presession, interview, intersession, intervention, and postsession (Tomm, 1984). The five-part session provides a structure for the development of a family systems nursing interview (Wright, Watson, \& Bell, 1990).

Presession. During the presession (15 to 30 minutes), the student presents the family genogram and highlights the events from the most recent interview. The student 
also presents salient information from an ongoing literature review about the presenting health problem, relevant family dynamics, and possible interventions. Students are encouraged to develop hypotheses for each presession and questions that can be used to explore each hypotheses. During the presession, the clinical supervisor and other graduate students facilitate a refinement of hypotheses and potential questions.

Interview. Each interview consists of drawing forth family members' beliefs about the problem, treatment, and outcome, and invites the consideration of alternate facilitative beliefs (Wright \& Nagy, 1993; Wright \& Simpson, 1991; Wright, Watson, \& Bell, 1990). We view the interview as more than simply a gathering of information/assessment. We consider the larger context of the interview as a therapeutic conversation that we hope will perturb the family system. Through the asking of questions by both nurse interviewer and family members (Wright, 1989), a new view of the problem co-evolves. During the interview, the graduate student receives additional questions from the faculty supervisor through the telephone intercom. During a "phone-in," the interview is briefly interrupted while the student answers the phone and receives the message. The student then informs the family of the message/question.

Intersession. The intersession discussion (10 to 20 minutes) consists of a pause in the interview during which time the graduate student meets with the team while the family waits. At this time information from the session is discussed, and multiple views/beliefs about the interaction between the family and the problem are entertained. Our clinical team works together to co-evolve alternate beliefs'/epistemology/opinions about the nature of the problem.

We also use a variation of the "closed" team discussion by giving family members the opportunity to observe our clinical nursing team's discussion. This manner of working enables the team to become a "reflecting team" (Anderson, 1987). While the team reflects, the family sits behind the mirror with the graduate student and observes the team's dialogue about the family's dialogue. Because the process of the reflecting team requires that our graduate students express their opinions in front of the family, students rapidly learn how to view problems in a positive frame 
and to be less judgmental toward the families. This unique intervention and tool was developed by

Tom Anderson (1987) of Norway.

End-of-session intervention/opinion.

Following a "closed team" discussion, the graduate student returns to the family and shares the team's ideas and opinions with the family. If a reflecting team was used, the graduate student and the family return to the interviewing room while the team returns to their original position behind the mirror. The student then pursues the family's opinions and the impact of the team's dialogue.

Postsession. When the Family leaves, our clinical team meets for a review of the family members' reactions to the end of session intervention/opinion or to the reflecting team's opinions. Tentative plans for the next family session are made. The student receives feedback from her faculty supervisor and colleagues on her clinical skills during the interview.

\section{Phone-ins in live supervision}

Live supervision affords nursing students immediate feedback on the development of their clinical assessment and intervention skills, particularly because of the "phone-in" technology. It also allows the faculty member and student to join in "seeing" similar family dynamics. From an of approximately 150 phone-ins made during live supervision, the most compelling recommendation that emerged was the need to be trained in the area of phone-ins (Wright, 1986). The analysis indicated that effective supervisors in clinical work with families (1) keep the phone-in short, not more than 25 seconds; (2) vary the content of the phone-in according to the level of the supervisee (e.g., beginning supervisees need more explicit script statements, while advanced supervisees need more global instructions; (3) give only content comments (not process); and 
(4) give a maximum of two instructions on each phone-in.

\section{Conclusion}

Family systems nursing supervision is exciting, stimulating, and challenging. However, there is a dearth of family systems nurse educators who have had the opportunity to be trained as supervisors. Consequently, nurse educators must learn as they go: read the literature on supervision of clinical work with families and live supervision in particular, invite feedback from students and families about their skills as supervisors; and be willing to "see" the world from behind a one-way mirror.

\section{References}

Anderson, T. (1987). The reflecting team: Dialogue and meta-dialogue in clinical work.

Family Process , 26, 415-428.

Kubie. L. (1958). Research into the process of supervision in psychoanalysis. Psychoanalytic Quarterly, 27, 226-236.

Liddle, H. A., Davidson, G.S., \& Barrett, M. J. (1988). Outcomes of live supervision: Trainee perspectives. In H.A. Liddle, D.C. Breunlin, R.C. Schwartz (Eds.), Handbook of family therapy training and supervision. New York: Guilford Press.

Maturana, H., \& Varela, F.. (1992). The tree of knowledge. The biological roots of human understanding. Boston : Shambhala.

Montalvo, B. (1973). Aspects of live supervision. Family Process, 12, 343-359.

O'Hanlon, W.H. \& Wilk, J. (1987). Shifting contexts: The generation of effective psychotherapy. New York: Guilford Press. 
Schwartz, R.C., Liddle, H.A. \& Breunlin, D.C. (1988). Muddles of live supervision. In H.A. Liddle, D.C. Breunlin, R.C. Schwartz (Eds), Handbook of family therapy training and supervision. New York: Guilford Press.

Tomm, K. (1984). One perspective on the Milan systemic approach to family therapy, Part II: Description of session, format, interviewing style and interventions. Journal of Marital and Family Therapy, 10, 253-271.

Tomm, K.M. \& Wright, L.M. (1979) Family therapy training: Perceptual, conceptual and executive skills. Family Process, 18, 227-250.

Watson, W.L. (1987). Intervening with aging families and Alzheimer's disease. In L.M. Wright \& M. Leahey (Eds.), Families and chronic illness. Springhouse, PA: Springhouse Corp.

Watson, W.L. \& Nanchoff-Glatt, M. (1990). A family Systems nursing approach to premenstrual syndrome. Clinical Nurse Specialist, 4, 3-9.

Watzlawick, P., Weakland, J. \& Fisch, R. (1974). Change: Principles of problem formation and problem Resolution. New York: W.W. Norton \& Co.

Wheeler, D., Avis, J.M., Miller, L.A. \& Chaney, S. (1985). Rethinking family therapy education and supervision: A Feminist model. Journal of Psychotherapy and the Family, 1, 53-71.

Wright, L.M. (1986). An analysis of live supervision "phone-ins" in family therapy. Journal of Marital and Family Therapy, $12,187-190$.

Wright, L.M. (1989). When clients ask questions: Enriching the therapeutic conversation. Family Therapy Networker, 13 (6), 15-16.

Wright, L.M., Bell, J.M., \& Rock, B.L. (1989). Smoking behavior and spouses: A case report. Family Systems Medicine, 7, 158-171. 
Wright, L.M., \& Leahey, M. (1984). Nurses and families:

A guide to family assessment and intervention.

Philadelphia: F.A. Davis Co.

Wright, L.M., \& Leahey, M. (1988). Nursing and family

Therapy training. In H.A. Liddle, D.C. Breunlin, \&

R.C. Schwartz (Eds.), Handbook of family therapy

training and supervision (pp. 278-289). New York: Guilford Press

Wright, L.M., \& Leahey, M. (1990). Trends in the nursing of

Families. Journal of Advanced Nursing, 15, 148-154.

Wright, L.M., \& Levac, A.M. (1992). The non-existence of non-compliant families: The influence of Humberto Maturana.

Journal of Advanced Nursing, 17, 913-917.

Wright, L.M. , Luckhurst, P. \& Amundson, J. (1990).

Family therapy supervision as counter-induction. Journal

of Family Psychotherapy, 1 (3), 65-74.

Wright, L.M., Miller, D. \& Nelson, K.L. (1985).

Treatment of a non-drinking family member in an alcoholic family systems by a family nursing team.

Family Systems Medicine, 3, 291-300.

Wright, L.M. \& Nagy, J. (1993). Death: The most Troublesome family secret of all. In E. Imber Black (Ed.), Secrets in families and family therapy. New York: W.W. Norton \& Co.

Wright, L.M. \& Simpson, P. (1991). A systemic belief approach to epileptic seizures: A case of being spellbound. Contemporary Family Therapy: An International Journal, 13, 165-180.

Wright, L.M. \& Watson, W. L. (1988). Systemic family therapy and family development. In J.C. Falicov (Ed.), Family transitions: Continuity and change over the life cycle, (pp. 407-430). New York: Guilford Press

Wright, L.M., Watson, W.L., \& Bell, J.M. (1990).

The family nursing unit: A unique integration of research, education, and clinical practice. In J.M. Bell, W.L. Watson \& L.M. Wright (Eds.), The cutting edge of family nursing (pp. 95-109). Calgary, Alberta: Family Nursing Unit Publications 